\title{
AGENESIA DEL LÓBULO HEPÁTICO DERECHO ASOCIADO A AGENESIA VESICULAR*
}

\author{
Drs. Domingo Montalvo V. ${ }^{1}$, Guillermo Castro G. ${ }^{1}$, Renato Alarcón E. ${ }^{1}$ \\ 1 Servicio de Cirugía Hospital Juan Noé Crevani. \\ Arica, Chile.
}

\begin{abstract}
\section{Agenesis of the right hepatic lobe associated with gallbladder agenesis}

Background: Anatomical abnormalities of the liver are rare and their association with gallbladder agenesis are even more uncommon. Case report: We report a 63 years old man complaining of jaundice, without pain or fever. A magnetic resonance imaging showed a right hepatic lobe agenesis associated with gallbladder agenesis. Jaundice subsided spontaneously.
\end{abstract}

Key words: Hepatic lobe agenesis, gallbladder agenesis, jaundice.

\section{Resumen}

Introducción: Las anomalías anatómicas del hígado son raras, la asociación a una agenesia vesicular es más infrecuente aún, siendo su diagnóstico generalmente un hallazgo. Caso clínico: Presentamos el caso de un paciente masculino de 63 años que consulta por ictericia, sin dolor ni fiebre, al cual se le realiza diagnóstico por imagen con resonancia magnética de agenesia de lóbulo hepático derecho asociado a agenesia vesicular. Dado que el paciente no tiene litiasis biliar, se decide tratamiento médico.

Palabras clave: Hígado, vesícula biliar, agenesia.

\section{Introducción}

La agenesia de lóbulos hepáticos es una condición poco frecuente y más infrecuente aún es la del lóbulo derecho, sin embargo, con el uso de más estudios de imágenes ha aumentado su diagnóstico ${ }^{1}$. La agenesia del lóbulo hepático derecho se define como la ausencia de tejido hepático lateral derecho a la cisura lobar principal, la cual contiene la vena hepática media; no debe haber una cirugía previa o enfermedad. También hay ausencia de la vena supra hepática derecha, de ramas portales derechas y no hay dilatación de los conductos derechos intra hepáticos ${ }^{2}$.

La primera descripción de agenesia de lóbulo derecho fue hecha por Heller ${ }^{3}$ en 1870. Habitualmente se presenta en forma asintomática y se asocia a hipertrofia de otros segmentos hepáticos, interpo-

\footnotetext{
Los autores no refieren conflictos de interés.

Correspondencia: Dr. Domingo Montalvo V. ddmontalvo@gmail.com
}

*Recibido el 25 de noviembre de 2014 y aceptado para publicación el 23 de febrero de 2015. 

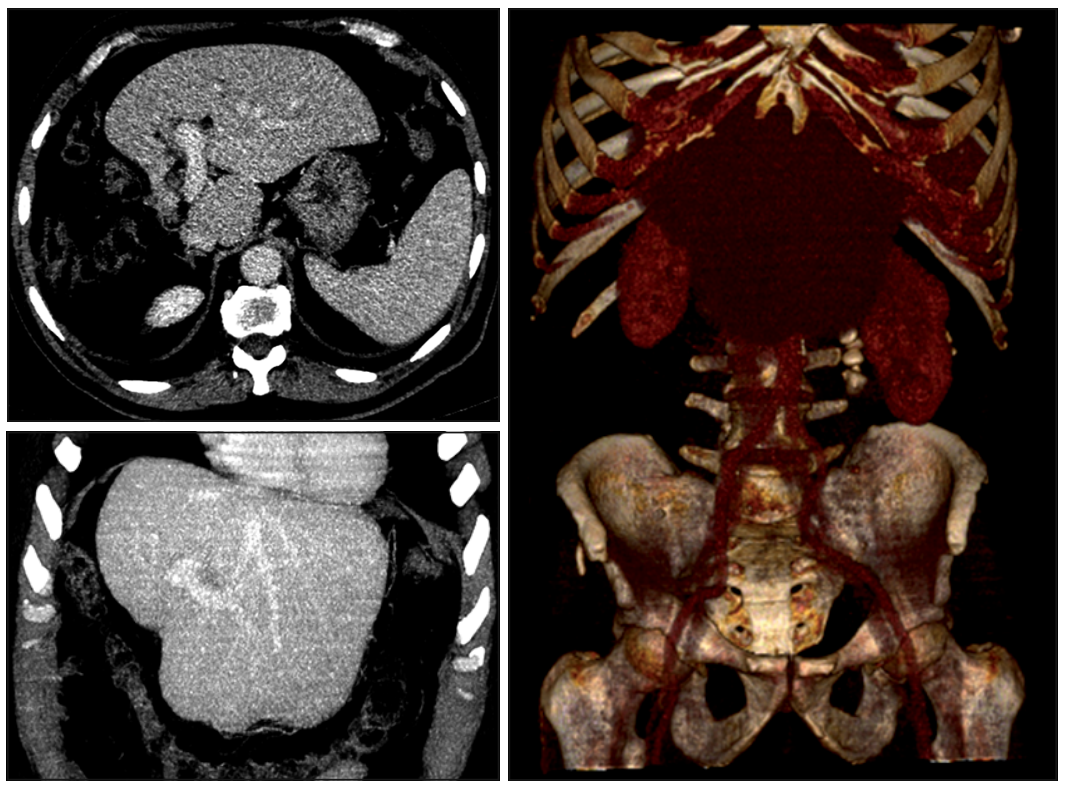

Figura 1. Tomografía computada, reconstrucción de proyección de máxima intensidad y volumétrica. Hígado con hipertrofia de lóbulo izquierdo y lóbulo caudado, asas intestinales ocupando el lecho hepático derecho, ausencia de lóbulo hepático derecho morfológico.

sición de colon, hernia diafragmática e hipertensión portal ${ }^{4}$. La vesícula se puede encontrar en posición superior, lateral o posterior, dificultando la colecistectomía.

La agenesia vesicular es una condición poco frecuente y se reporta en el $0,007-0,027 \%$ de las colecistectomías ${ }^{5}$, fue comunicada por primera vez por Lemery ${ }^{6}$ en 1701 . Se puede presentar en forma asintomática, sin embargo, hasta el $50 \%$ de los pacientes presentan dolores cólicos similares a la colelitiasis sintomática. Ecográficamente se puede confundir con vesículas escleroatróficas o colecistitis alitiásicas.

\section{Caso clínico}

Paciente de 63 años sin antecedentes mórbidos, consultó por cuadro de dolor abdominal cólico en hipocondrio derecho, asociado a ictericia. Se realizaron exámenes de laboratorio donde destaca un patrón colestásico obstructivo, con bilirrubina total de $7,86 \mathrm{mg} / \mathrm{dl}$, fosfatasas alcalinas de $249 \mathrm{UI} / \mathrm{L}$ y GGT de 502 UI/L. Se realizó una ecografía abdominal (ECO) donde se describe agenesia del lóbulo hepático derecho y probable agenesia vesicular.

Se tomó una Tomografía Computada (TC) donde se describe sólo el lóbulo hepático izquierdo, sin identificar hígado derecho, ni venas hepáticas derechas; tampoco se describe vesícula biliar (Figuras 1 y 2). Se realiza Colangio Resonancia Nuclear Mag-

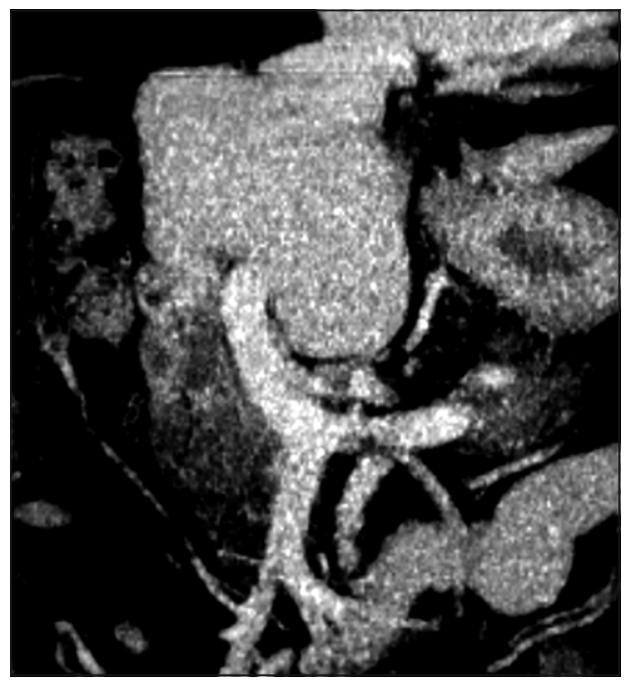

Figura 2. Proyección de máxima intensidad de tomografía computada. Vena porta sin ramificación derecha, se continua como estructura única a vena porta izquierda.

nética (ColangioRNM) donde tampoco se describe tejido hepático derecho ni estructuras vasculares ipsilaterales; ni se describe vesícula biliar. En los estudios de imágenes no se describen imágenes endoluminales coledocianas, ni estenosis de la vía biliar.

El paciente presentó una buena evolución con mejoría espontánea de la ictericia y del dolor abdominal. 


\section{Discusión}

La agenesia del lóbulo hepático derecho es una entidad infrecuente que es diagnosticada incidentalmente por estudio de imágenes. En nuestro caso, la patología fue diagnosticada por un síndrome ictérico, caracterizado por aumento de las transaminasas y de la bilirrubina directa, la que tuvo una regresión a la normalidad sólo con régimen cero, no así las transaminasas las que se mantuvieron en rango elevado sin producir esto alteración en las imágenes ni en la clínica del paciente.

Existen dos tipos de agenesia del lóbulo hepá$\mathrm{tico}^{7}$, la que es secundaria a patologías digestivas como son la hidatidosis hepática, enfermedades trombóticas porto-venosas, cirrosis con necrosis y patología coledociana obstructiva, todas ellas generando una atrofia lobar hepática secundaria. El otro tipo de agenesia, que corresponde a este caso en particular, es la agenesia congénita, la que puede estar acompañada de diferentes anomalías anatómicas, ya sea en vías biliares, diafragma, pulmón y/o mal rotación de órganos intra abdominales. Asociado a su patología de base, se puede desarrollar hipertensión portal (HTP) y várices esofágicas secundarias, especialmente cuando no hay una hipertrofia secundaria en el lóbulo hepático izquierdo, aunque aún no está clara la fisiopatología de esta HTP. Ésta también puede ser una causa de sangrado digestivo alto en menores de 30 años. Este paciente además se presenta con agenesia vesicular, patología que tiene una prevalencia de $0,007-0,027 \%$ de las colecistectomías $\mathrm{y}$ en algunos casos se asocia a coledocolitiasis. Al no haber sospecha de coledocolitiasis en los exámenes de imágenes, ColangioRNM, TC y ECO, se decidió finalmente por tratamiento espectante.

Una duda razonable del equipo médico en la mayoría de las publicaciones es definir el mejor abordaje quirúrgico en pacientes con agenesia del lóbulo hepático derecho y colelitiasis, dada la mayor probabilidad de alteraciones anatómicas y la consiguiente probabilidad de lesión de vía biliar, la que sin duda no debe ser abordada sin antes tener un cabal conocimiento de la posición exacta de los conductos biliares. La cirugía laparoscópica no está formalmente contraindicada, dependerá de la experiencia quirúrgica del equipo ${ }^{8}$. Teniendo en cuenta esto, es necesario también modificar la posición de los trocares de laparoscopia, ya que dentro de las variaciones descritas de la vesícula, ésta se puede encontrar mucho más central o incluso hacia la derecha del lóbulo hepático izquierdo, el que puede o no estar hipertrofiado ${ }^{4,7}$.

\section{Conclusión}

La agenesia de un lóbulo hepático, supone una rara condición médica, que debe ser considerada, pues será pesquisada cada vez con mayor frecuencia dada la gran cantidad de exámenes de imágenes solicitados; el cirujano y el equipo médico que trate al paciente tendrá que tener en cuenta las variables y tratamientos que debemos ofrecer en estos casos.

\section{Referencias}

1. Radin DR, Colletti PM, Ralls PW, Boswell WD, Halls JM. Agenesis of the right lobe of the liver. Radiology 1987;164:639-42.

2. Champetier J, Yver R, Letoublon C, Vigneau B. A general review of anomalies of hepatic morphology and their implications. Anat Clin. 1985;7:285-99.

3. Heller A. Mangelhafte Entwicklung des rechten Leberlappens. Vir-chows Arch. 1870;51:135.

4. Iannelli A, Facchiano E, Fabiani P, Sejor E, Bernard JL, Niezar E, et al. Agenesis of the right liver: a difficult laparoscopic cholecystectomy. J Laparoendosc Adv Surg Tech A. 2005; 15:166-9.

5. Cano-Valderrama Ó, Talavera P, Domínguez-Serrano I, Sánchez-Pernaute A, Torres García AJ. Agenesia de la vesícula biliar. A propósito de un caso. Cir Esp. 2011;89:471-2.

6. Baltazar U, Dunn J, González-Díaz S, Browder W. Agenesis of the gallbladder. South Med J. 2000;93: 914-15.

7. Lucas Souto Nacif, Yuri dos Santos Buscariolli. Case Report Agenesis of the Right Hepatic Lobe. Case Rep Med. 2012;2012:415742. doi: 10.1155/2012/415742. Epub 2012 Mar 21.

8. Jiménez Fuertes M, López Andújar R, Lloret Larrea M, Moya Herráiz A, Mir Pallardó J. Agenesia del lóbulo hepático derecho. ¿Dónde está la vesícula? Cir Esp. 2007;82:239-40. 